\title{
Regulation of Toll-Like Receptor Expression in Human Conjunctival Epithelial Cells
}

\author{
Jing Li, ${ }^{1}$ Melina Setiawan, ${ }^{1}$ Hong Wu, ${ }^{2}$ Roger W. Beuerman, ${ }^{1,3}$ and Peiquan Zhao ${ }^{1}$ \\ ${ }^{1}$ Department of Ophthalmology, Xinhua Hospital Affiliated to Shanghai Jiao Tong University School of Medicine, \\ 1665 Kong Jiang Road, Shanghai 200092, China \\ ${ }^{2}$ Department of Ophthalmology, Second Hospital of Jilin University, Changchun 130041, China \\ ${ }^{3}$ Singapore Eye Research Institute, 11 Third Hospital Avenue, Singapore 168751
}

Correspondence should be addressed to Peiquan Zhao; zhaopeiquan@126.com

Received 27 March 2014; Accepted 11 May 2014; Published 25 May 2014

Academic Editor: Valentin Huerva

Copyright (C) 2014 Jing Li et al. This is an open access article distributed under the Creative Commons Attribution License, which permits unrestricted use, distribution, and reproduction in any medium, provided the original work is properly cited.

\begin{abstract}
Previous studies showed marked decrease of multiple Toll-like receptor (TLR) expression in corneal and conjunctival epithelial cells upon culture in vitro. The aim of this study was to identify factor(s) which regulate TLR expression. Primary human conjunctival epithelial cells and immortal conjunctival (IOBA-NHC) and corneal epithelial cell lines (HCET) were used. The effect of various cytokines, hypoxia, mechanical wounding, and airlifting culture on TLR expression was examined by quantitative PCR and western blot analysis. Ligand stimulated TLR activation was analyzed. TLR mRNA expression increased modestly when cultured monolayered cells were stimulated by TNF- $\alpha$, IL- $\alpha$, IL- $1 \beta$, IL-6, IL-8, IFN- $\gamma$ (about 2 -fold), hypoxia (2.1- to 4.8 -fold selectively), and wounding (3.1- to 9.3-fold). In airlifted multilayered cells, TLR expression increased 7.8- to 25.9-fold compared to monolayered cells. Airlifted cells showed increased response to low concentrations of lipopolysaccharide (LPS) and peptidoglycan (PGN) stimulation. $\mathrm{NF} \kappa \mathrm{B}$ inhibition prevented the formation of cell sheets and led to the collapse of already-formed multilayered structure and the simultaneous reduction of TLR mRNA level. In conclusion, our study showed that the conjunctival epithelial cell expressed TLR was sensitive to various stimulants, and a multilayered epithelium-like structure was needed to maintain TLR expression.
\end{abstract}

\section{Introduction}

Toll-like receptors (TLRs) are a family of pattern-recognition receptors [1]. Ten TLR proteins have been identified in human cells. Each TLR binds specific pathogen-associated molecular patterns (PAMPs) of viruses, bacteria, fungi, and parasites. Some TLRs, such as TLR3 and TLR4, also recognize damageassociated molecular patterns (DAMPs) released by injured cells [2]. The activation of TLR and its associated signaling pathway leads to a broad range of inflammatory responses mediated mainly by increased secretion of cytokines [3].

Ocular surface epithelial cells, namely, conjunctival and corneal epithelial cells, were known to express multiple TLRs [4-6]. Cultured monolayer cells were most often used to study the expression, function, and regulation of TLR in epithelial cells. While the most TLR expressed in epithelial cells showed responses to its ligands in cultured cells, contradictory results were reported on the biological activity of
TLR2 and TLR4 in corneal and conjunctival epithelial cells [7-9]. In a previous study, we quantified and compared the expressions of multiple TLRs in primary cultured human conjunctival epithelial cells and conjunctival epithelium tissue and found that TLR expressions in cultured cells were much lower than those in undigested tissue [6]. Here, we explored the effect of multiple factors on TLR expression and report that the multilayered structure was a key factor to maintain a normal level of TLR expression in conjunctival and corneal epithelial cells.

\section{Materials and Methods}

2.1. Reagents. Unless otherwise specified, all cell culture medium and supplements were purchased from Life Technologies (Carlsbad, CA, USA). All plasticware for cell culture was purchased from Greiner Bio-One (Frickenhausen, 
Germany). General reagents for sodium dodecyl sulfate polyacrylamide gel electrophoresis (SDS-PAGE) and western blot were purchased from Bio-Rad (Hercules, CA, USA). Lipopolysaccharide (LPS) isolated from Pseudomonas aeruginosa and peptidoglycan (PGN) isolated from Bacillus subtilis were purchased from Sigma-Aldrich (St. Louis, MO, USA). 5Aminosalicylic acid (5-ASA, NF $\kappa$ B inhibitor) was purchased from Santa Cruz Biotechnology (Dallas, TX, USA).

\subsection{Primary Conjunctival Epithelial Cell Isolation and Culture.} Primary human conjunctival epithelial cells were isolated from cadaver conjunctival tissue obtained from Singapore Eye Bank as described before [10]. Briefly, after antibiotics/PBS washing, the conjunctival tissue was cut into small pieces and placed on cell culture plate with one drop of full medium which contained equal volume of DMEM and F12, $10 \%$ fetal bovine serum (FBS), $0.5 \mu \mathrm{g} / \mathrm{mL}$ hydrocortisone, $10 \mathrm{nM}$ cholera toxin, $10 \mathrm{ng} / \mathrm{mL}$ human epidermal growth factor (hEGF), $5 \mu \mathrm{g} / \mathrm{mL}$ insulin, and antibiotics. Epithelial cell outgrowth was observed 2-3 days later, and the culture was maintained for 4-5 days before the tissues were discarded. The cells were then submerged-cultured in the same medium for further propagation. Passage 2 to 3 cells were used in this study. The study protocol was approved by the Institutional Review Board of Singapore Eye Research Institute and followed the tenets of the Declaration of Helsinki.

2.3. Conjunctival and Corneal Epithelial Cell Lines. Immortalized human conjunctival epithelial cell (IOBA-NHC) was a gift from Dr. Diebold at the University of Valladolid, Spain [11]. SV40 large T-antigen immortalized human corneal epithelial cell (HCET) was purchased from Riken Cell Bank (Ibaraki, Japan) [12]. Both cells were cultured in the same medium as the primary conjunctival epithelial cells.

\subsection{Cell Treatment}

2.4.1. Culture Supplement. A basic medium was prepared first which contained equal volume of DMEM and F12 with antibiotics. The following supplements were added individually to the basic medium: $1 \mu \mathrm{g} / \mathrm{mL}$ bovine insulin, $2 \mathrm{ng} / \mathrm{mL}$ recombinant hEGF, $0.5 \mu \mathrm{g} / \mathrm{mL}$ hydrocortisone, $10 \% \mathrm{FBS}$, and $0.1 \mu \mathrm{g} / \mathrm{mL}$ cholera toxin. The isolated primary human conjunctival epithelial cells were submerged in the above medium for $24 \mathrm{hrs}$, and TLR mRNA expression was compared to cells grown in full and basic medium.

2.4.2. Airlifted Culture. Airlifted culture refers to the culture condition in which cells were grown at the air-medium interphase. To achieve this, submerged-cultured cells were trypsinized and seeded on BioCoat collagen I coated 6well inserts with 3.0 micron pore (BD Biosciences, San Jose, CA, USA). Cells in the inserts were submerged in the full medium for the first $24 \mathrm{hrs}$ and continued in a medium which contained DMEM : F12 (3:1, V : V) with the same supplement as in the full medium, and the volume of medium was reduced so that only the bottom of the insert was in contact with the medium (about $1 \mathrm{~mL}$ per well). Epithelial cells started to form multilayered sheet after 3 days. The culture was maintained for 7-12 days depending on the progression of cell stratification, and the culture medium was changed every day.

2.4.3. Cytokine Stimulation. Selected cytokines were added to $80-90 \%$ confluent submerged cells for $24 \mathrm{hrs}$ before the supernatant was harvested for cytokine secretion analysis.

2.4.4. Cell Wounding. Eight to ten parallel scratches were made to $80-90 \%$ confluent submerged cells at about $1 \mathrm{~cm}$ space using a sterile surgical blade. Cells were then washed with PBS and given fresh medium after wounding. Supernatant was harvested $24 \mathrm{hrs}$ later for cytokine secretion analysis.

2.4.5. Hypoxia Stimulation. Hypoxia stimulation was achieved by culturing submerged cells in $37^{\circ} \mathrm{C}$ incubator with $95 \%$ nitrogen and $5 \%$ carbon dioxide for $24 \mathrm{hrs}$.

2.5. Quantitative PCR ( $q P C R$ ) Analysis. Total RNA was extracted using NucleoSpin RNA II (Macherey-Nagel, Germany) and transcribed into cDNA using SuperScript III Reverse Transcriptase from Life Technologies. qPCR was performed using Taqman real-time PCR reagents as previously described [6]. $\beta$-Actin was used as internal control. The mRNA expression was calculated by the comparative expression methods of $2^{(-\delta \delta \mathrm{Ct})}$, where $\delta \mathrm{Ct}$ is the threshold cycle and $\delta \delta \mathrm{Ct}=\delta \mathrm{Ct}_{\text {airlifted }}-\delta \mathrm{Ct}_{\text {submerged }}$.

2.6. Western Blot Analysis. Cells were lysed in RIPA buffer containing $10 \mathrm{mM}$ Tris $\mathrm{pH} 7.5,150 \mathrm{mM} \mathrm{NaCl}, 1 \%$ sodium deoxycholate, $1 \%$ Triton X-100, $1 \mathrm{mM}$ EDTA, and a protease inhibitor cocktail (Roche Diagnostics Asia Pacific, Singapore). Protein concentration was measured by Pierce Micro BCA Protein Assay Kit (Thermo Scientific, Rockford, IL, USA). Thirty micrograms of the total lysates was resolved on SDS-PAGE and transferred to nitrocellulose membrane. Blots were probed with the following antibodies at $4^{\circ} \mathrm{C}$ overnight: goat anti-TLR1 antibody (R\&D Systems, Minneapolis, MN) at the concentration of $2 \mathrm{ng} /$ lane; monoclonal anti-TLR2 and anti-TLR3 at the dilution of 1:100 (Imgenex, San Diego, CA); rabbit anti-TLR4, rabbit anti-TLR5, and goat antiTLR6 antibodies (Santa Cruz Biotechnology, Santa Cruz, CA) at the dilution of 1:200; and monoclonal anti-TLR9 antibody (Abcam, Cambridge, UK) at the concentration of $1 \mu \mathrm{g} / \mathrm{mL}$. Horseradish peroxidase conjugated species-specific secondary antibody (Santa Cruz Biotechnology, Santa Cruz, CA) incubation was carried out at room temperature for $1 \mathrm{hr}$ (1:2000 for anti-rabbit antibody sc-2030; 1:2000 for antimouse antibody sc-2005; and 1:5000 for anti-goat antibody sc-2350). The resulting immune complex was visualized using SuperSignal chemiluminescent substrates (Thermo Scientific, Rockford, IL, USA) and exposed to X-ray film.

2.7. IL-6 and IL-8 Secretion Analysis. IL-6 and IL-8 secretion was analyzed in the culture medium using OptEIA (BD Biosciences, USA) and corrected by total cellular protein and 


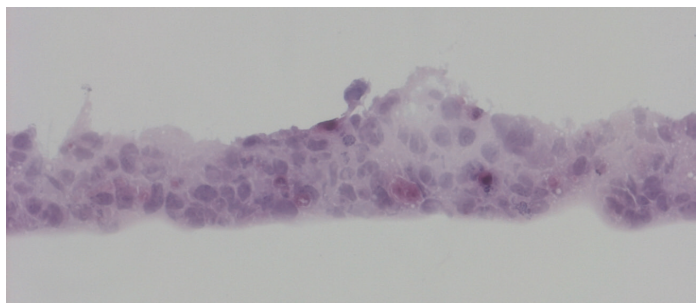

(a)

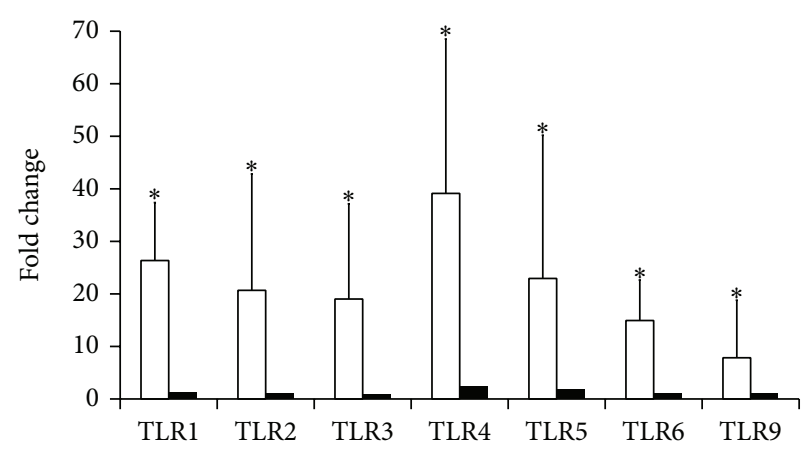

(b)

FIgURE 1: TLR mRNA expression in airlifted primary human conjunctival epithelial cells. (a) Hematoxylin and eosin staining of a representative cell sheet 7 days after airlifting culture. Typically, the cell sheet was composed of 3-4 layers of cells. Cells at the bottom were mostly cuboidal and more compact than the cells at the upper layers. (b) Averaged fold increase of individual TLR mRNA in airlifted (white bars) and replated conjunctival epithelial cells (black bars). Cells were harvested 10 days after airlifting culture. Half of the cells were replated to 6-well plate and submerged-cultured for $24 \mathrm{hrs}$ in 1:1 medium with full supplement before being lysed for RNA extraction. TLR mRNA level was determined by qPCR and compared to the same batch of cells submerged-cultured. Three different batches of cells were analyzed, and the fold increase was averaged. $Y$ error bars represent the standard deviation of the averaged results. Asterisks $(*)$ denote significant difference $(P<0.05)$ between airlifted and replated cells.

total medium volume. For each experiment, an aliquot of the culture medium was saved, briefly spun, and stored at $-80^{\circ} \mathrm{C}$ for ELISA analysis. Total medium volume $(\mathrm{mL})$ at the time of harvesting was recorded. Cells were washed in PBS twice and lysed, and total protein content was measured with Pierce Micro BCA Protein Assay Kit. IL-6 and IL-8 secretion was expressed as follows: cytokine concentration $(\mathrm{pg} / \mathrm{mL})$ multiplied by total medium $(\mathrm{mL})$ volume divided by total cell protein content (mg). The final unit was pg cytokine/mg cell protein.

2.8. NFKB Activity Analysis. The activities of $\mathrm{p} 65$ and $\mathrm{p} 50$ subunits of $\mathrm{NF} \kappa \mathrm{B}$ were measured by ELISA analysis using 96-well plates precoated with $\mathrm{NF} \kappa \mathrm{B}$-binding DNA consensus sequence (Pierce, Rockford, IL). Only the active form of p65 and p50 binds to the immobilized DNA sequence, and the bound protein was subsequently detected by specific primary antibody against p65 and p50 followed by HRP conjugated secondary antibody. The chemiluminescence signal was measured by Victor X3 microplate reader (Perkin Elmer, China). Data were expressed as the mean $\pm \mathrm{SE}$.

2.9. Statistical Analysis. Data were expressed as mean \pm standard deviation and analyzed by analysis of variance (ANOVA) after Levene's test for homogeneity, followed by the Fisher least significant difference (LSD) test. A probability level of $P<0.05$ was considered as statistically significant.

\section{Results}

3.1. Culture Medium Supplements Had No Effect on TLR Gene Expression in Primary Cultured Conjunctival Epithelial Cells. No changes in TLR mRNA expression were measured by qPCR in monolayered cells cultured in the basic medium with additional insulin, recombinant hEGF, hydrocortisone, FBS, or cholera toxin (data not shown).

3.2. Airlifting Culture Stimulated TLR $m R N A$ and Protein Expression. Primary conjunctival epithelial cells formed multilayered, stratified structure when airlifted (Figure 1(a)). Increased TLR mRNA expression was first detected by qPCR in cells 3 days after airlifting and continued to increase as cells form stratified sheets. Table 1 lists the $\delta$ Ct values for TLR mRNA in submerged and 10-day airlifted primary human conjunctival cells. The averaged fold increase of each TLR mRNA is presented in Figure 1(b). TLR4 mRNA expression as detected in only one batch of submerged primary cells but in all airlifted cells.

Next, we replated the airlifted primary cells on 6-well plate and maintained at submerged condition. Less than $10 \%$ of the cells adhered to the culture dish after $24 \mathrm{hrs}$. TLR mRNA expression decreased to levels prior to airlifting culture (Figure 1(b)). In cells which had no detectable amount of TLR4 mRNA, it remained positive when the airlifted cells were replated.

The same experiments were repeated in immortalized human corneal (HCET) and conjunctival epithelial cells (IOBA-NHC). Differences in TLR mRNA expression were noticed (Table 1). TLR6 mRNA expression was not detected in HCET cells by qPCR. Airlifting culture induced further increase of all TLR mRNA in both cell lines, however, at a smaller magnitude than the primary cells (Figures 2(a) and 2(b)).

Due to the limited availability of primary human cells, we used IOBA-NHC cells to compare the changes of TLR protein expression before and after airlifting culture. Western blot analysis revealed increased TLR1, TLR2, TLR3, TLR4, and TLR5 expression, which largely matched the increase of the respective mRNA (Figures 2(c) and 2(d)). Because TLR2 and TLR5 were barely detectable in submerged-cultured 


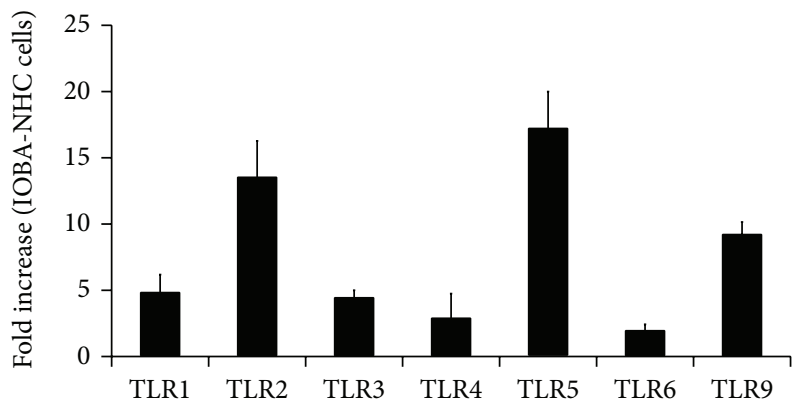

(a)

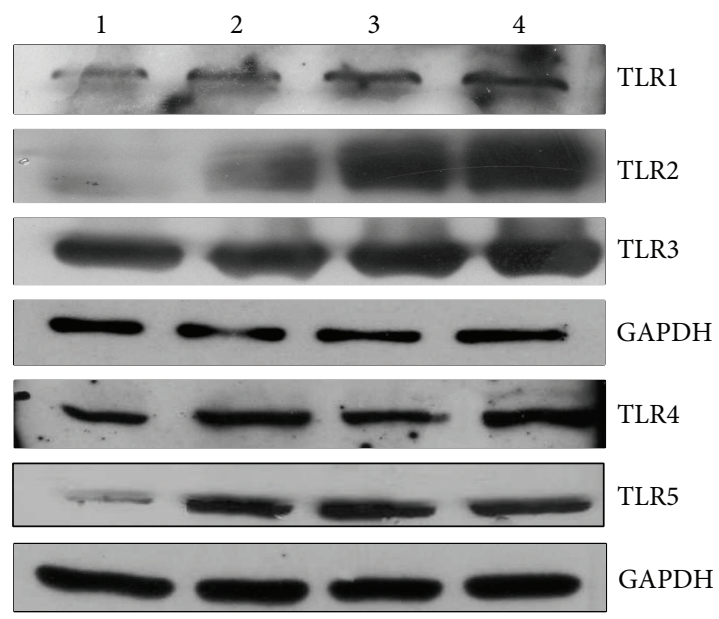

(c)

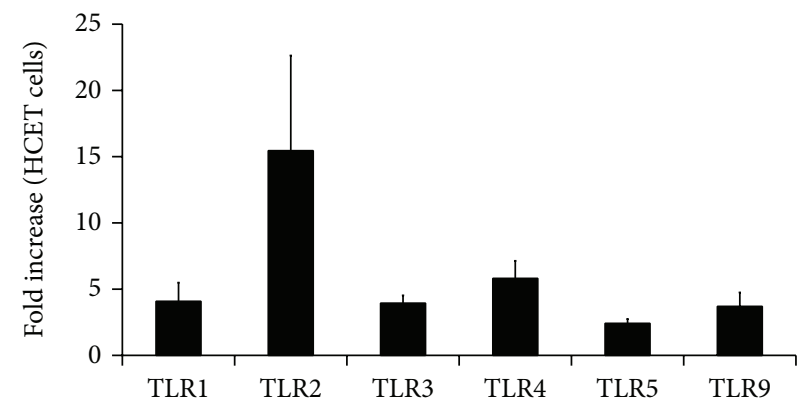

(b)

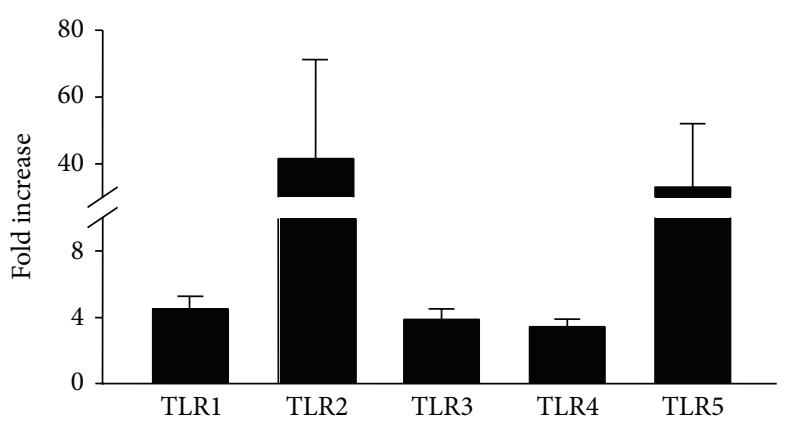

(d)

FIGURE 2: TLR mRNA and protein expression in airlifted immortal human corneal (HCET) and conjunctival epithelial cells (IOBA-NHC). (a) Averaged fold increase of TLR mRNA in IOBA-NHC cells. The increase was statistically significant for each TLR. (b) Averaged fold increase of TLR mRNA in HCET cells. The increase was statistically significant for each TLR. Cells were airlifted for 10 days. TLR mRNA level was determined by qPCR and compared to submerged cells. The experiment was repeated 3 times. $Y$ error bars represent the standard deviation of the averaged results. (c) Micrographs of a representative western blot showing TLR protein expression in IOBA-NHC cells. Lane 1: submerged-cultured; lane 2: 3 days after airlifting culture; lane 3: 7 days after airlifting culture; lane 4: 10 days after airlifting culture. Glyceraldehyde 3-phosphate dehydrogenase (GAPDH) protein was probed as loading control. (d) Averaged TLR protein increase in IOBANHC cells 10 days after airlifting culture compared to submerged-cultured cells. X-ray films from 2 independent western blot experiments were scanned in a densitometer, and the results were averaged. The increase was statistically significant for each TLR protein tested.

TABLE 1: $\triangle \mathrm{Ct}$ of individual TLR mRNA in submerged and airlifted primary human conjunctival epithelial cells, immortalized human conjunctival epithelial cells (IOBA-NHC), and immortalized human corneal epithelial cells (HCET).

\begin{tabular}{|c|c|c|c|c|c|c|}
\hline \multirow[t]{2}{*}{ mRNA } & \multicolumn{2}{|c|}{$\begin{array}{l}\text { Primary conjunctival epithelial cells } \\
\qquad(n=3)\end{array}$} & \multicolumn{2}{|c|}{ IOBA-NHC cells } & \multicolumn{2}{|c|}{ HCET cells } \\
\hline & Submerged & Airlifted & Submerged & Airlifted & Submerged & Airlifted \\
\hline TLR1 & $10.97 \pm 1.08$ & $6.27 \pm 0.72$ & $7.02 \pm 0.36$ & $4.77 \pm 0.42$ & $10.58 \pm 0.03$ & $8.55 \pm 0.14$ \\
\hline TLR2 & $10.51 \pm 1.84$ & $6.14 \pm 1.32$ & $8.92 \pm 0.24$ & $5.17 \pm 0.56$ & $5.93 \pm 0.38$ & $1.98 \pm 0.18$ \\
\hline TLR3 & $9.13 \pm 1.93$ & $4.88 \pm 1.23$ & $4.69 \pm 0.18$ & $2.57 \pm 0.38$ & $4.63 \pm 0.17$ & $2.65 \pm 0.26$ \\
\hline TLR4 & $14.93(n=1)$ & $9.74 \pm 1.01$ & $3.06 \pm 0.14$ & $1.57 \pm 0.30$ & $7.25 \pm 0.04$ & $4.71 \pm 0.10$ \\
\hline TLR5 & $10.61 \pm 2.08$ & $6.28 \pm 1.13$ & $10.85 \pm 1.79$ & $6.75 \pm 0.18$ & $5.64 \pm 0.17$ & $4.36 \pm 0.09$ \\
\hline TLR6 & $12.41 \pm 1.02$ & $8.51 \pm 0.53$ & $5.39 \pm 0.48$ & $4.48 \pm 0.51$ & $\mathrm{ND}$ & ND \\
\hline TLR9 & $13.32 \pm 1.19$ & $10.36 \pm 0.78$ & $9.54 \pm 0.73$ & $6.35 \pm 0.16$ & $10.10 \pm 0.46$ & $8.21 \pm 0.79$ \\
\hline
\end{tabular}

$\Delta \mathrm{Ct}$ was calculated using $\beta$-actin as internal control. Data was presented as average \pm standard deviation. The experiment was performed three times for each condition. For primary cells, the results shown were the averaged $\delta \mathrm{Ct}$ of three different batches of cells. "Submerged" refers to submerged-cultured cells at $80-$ $90 \%$ confluence. "Airlifted" refers to airlifted culture at 10 days. ND stands for nondetected. 


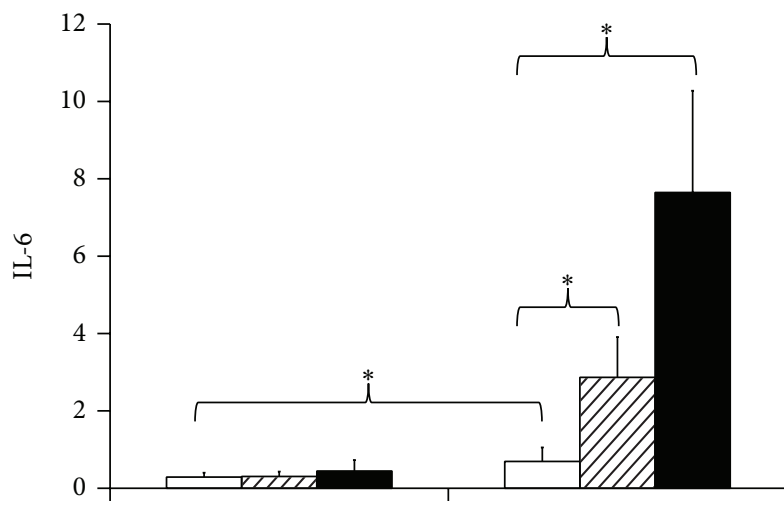

Cj submerged

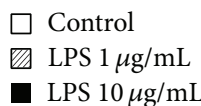

- LPS $10 \mu \mathrm{g} / \mathrm{mL}$

(a)

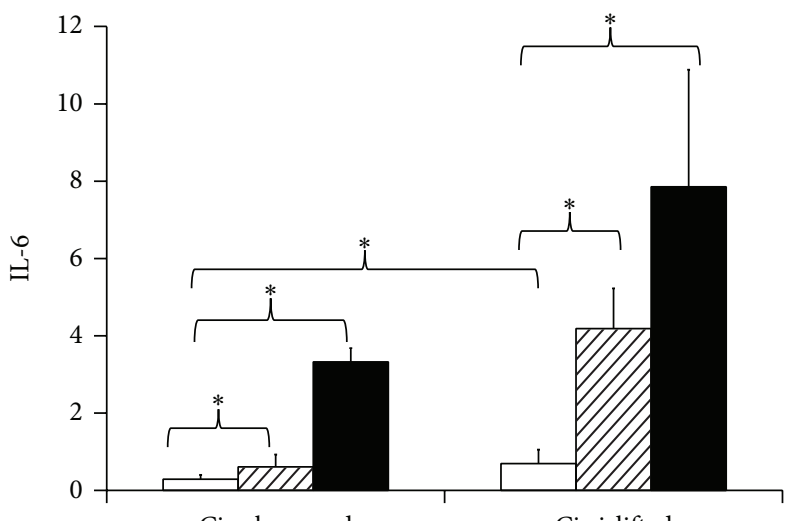

Cj submerged

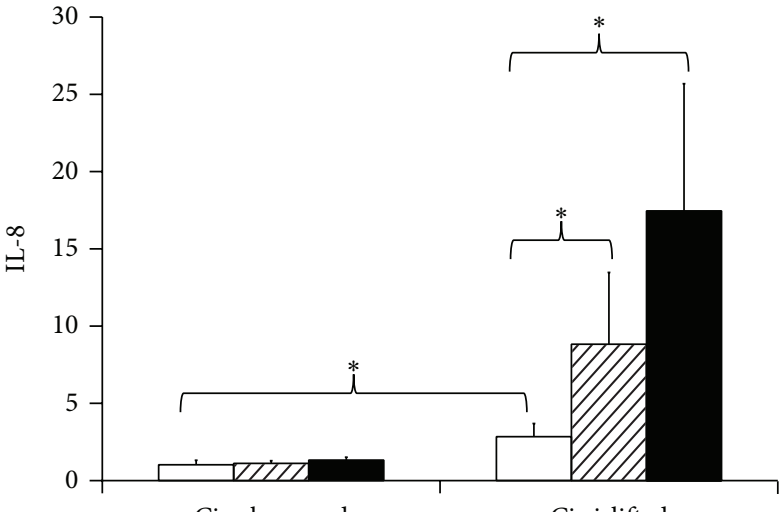

Cj submerged

$\mathrm{Cj}$ airlifted
团 LPS $1 \mu \mathrm{g} / \mathrm{mL}$

- LPS $10 \mu \mathrm{g} / \mathrm{mL}$

(b)

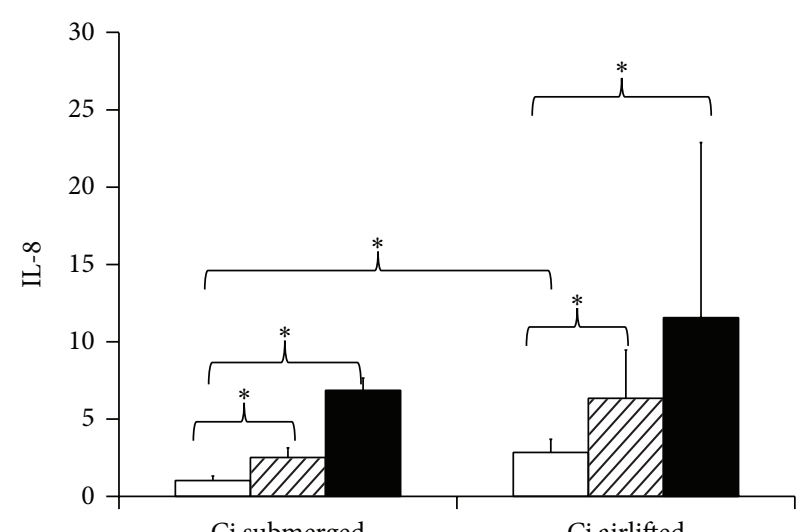

Cj submerged

Cj airlifted

Control

PGN $100 \mathrm{ng} / \mathrm{mL}$

PGN $1 \mu \mathrm{g} / \mathrm{mL}$

(c)

(d)

FIGURE 3: LPS and PGN stimulated IL-6 and IL-8 secretion in submerged and airlifted primary conjunctival epithelial cells. (a) LPS stimulated IL-6 secretion. (b) LPS stimulated IL-8 secretion. (c) PGN stimulated IL-6 secretion. (d) PGN stimulated IL-8 secretion. IL-6 and IL-8 concentrations were expressed as $\mathrm{pg} / \mathrm{mL}$ medium $/ \mathrm{mg}$ total cellular protein. Asterisks $(*)$ denote significant difference $(P<0.05$ by paired $t$-test) between two groups. $Y$ error bars represent the standard deviation of the averaged results from 3 different experiments.

IOBA-NHC cells, the calculated increase for the protein was greater than that for its respective mRNA. Similar results were obtained from HCE cells (data not shown).

\subsection{Airlifted Conjunctival Epithelial Cells Responded to Low} Concentrations of LPS and PGN Stimulation. To test the effect of increased TLR expression in airlifted cells, we compared LPS and PGN stimulated IL- 6 and IL- 8 secretion in primary conjunctival epithelial cells cultured under submerged and airlifted conditions.

Compared to submerged culture, airlifting required less medium level and had higher cell density. To correct for these differences, we calculated cytokine concentrations in the unit of $\mathrm{pg} / \mathrm{mL}$ medium $/ \mathrm{mg}$ total cell protein. We found that both
IL-6 and IL-8 concentrations were significantly higher in the airlifting culture medium than in the submerging culture medium without added ligands (Figure 3 ).

When incubated with 1 and $10 \mu \mathrm{g} / \mathrm{mL}$ LPS for $24 \mathrm{hrs}$, only airlifted cells showed increased IL- 6 and IL- 8 secretion. No significant changes were measured in the submergedcultured cells (Figures 3(a) and 3(b)).

When incubated with $100 \mathrm{ng} / \mathrm{mL}$ and $1 \mu \mathrm{g} / \mathrm{mL}$ PGN for $24 \mathrm{hrs}$, the airlifted cells showed more increase of both IL-6 and IL-8 compared to the submerged cells (Figures 3(c) and $3(\mathrm{~d}))$.

3.4. Airlifted Conjunctival Epithelial Cells Were Sensitive to $N F \kappa B$ Inhibition. In an attempt to explore the mechanisms 


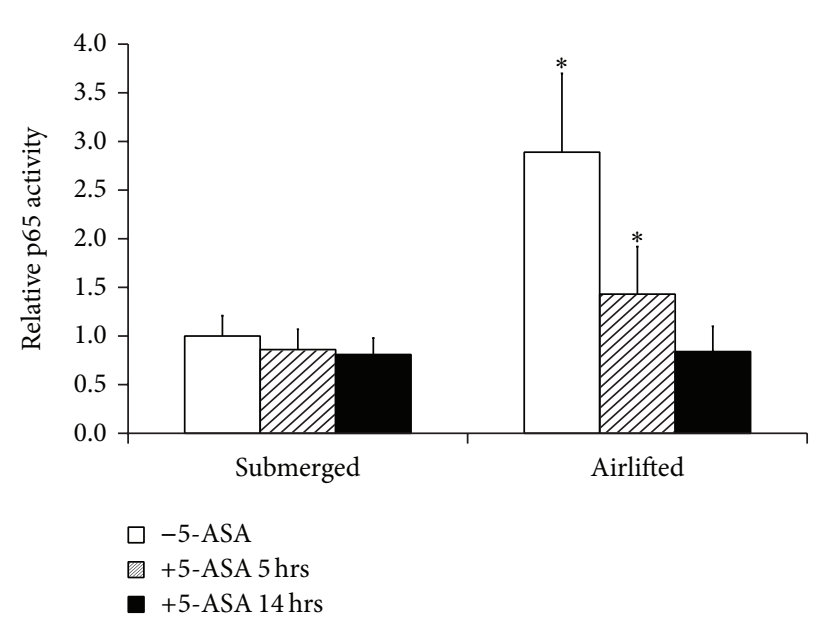

(a)

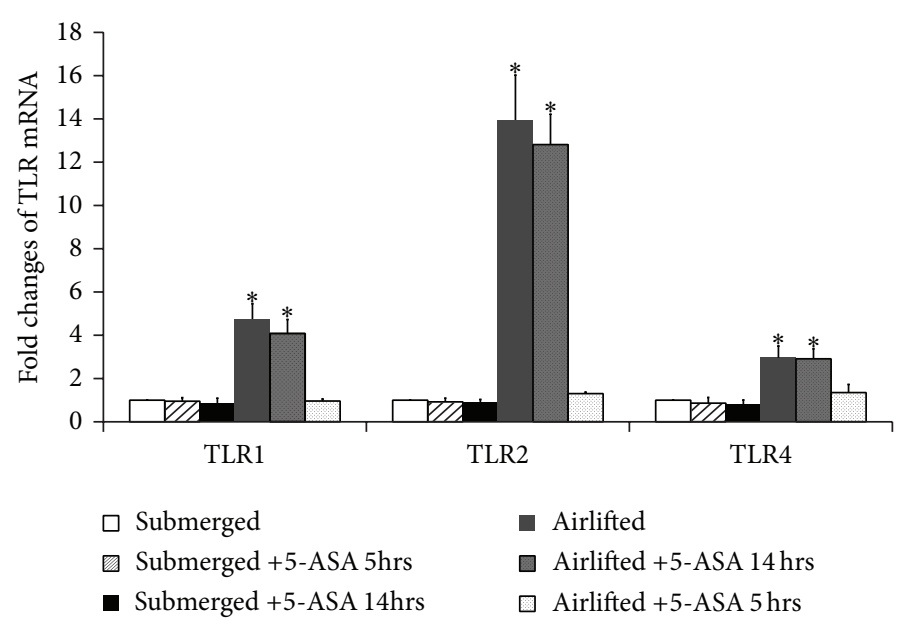

(b)

FIGURE 4: The effect of NF $\kappa$ B inhibition on airlifted IOBA-NHC TLR expression. (a) Relative activity of p65 in submerged and airlifted IOBA-NHC cells with and without 5-ASA. p65 activity in submerged monolayer cells without 5-ASA was set as 1, and the activities of other cell conditions were compared to it. Asterisks $(*)$ denote significant difference $(P<0.05)$ between airlifted and submerged cells under the same treatment. (b) Fold changes of selective TLR mRNA expression by qPCR. Individual TLR expression in submerged monolayer cells without 5-ASA was used as control to calculate the fold change. Asterisks $(*)$ denote significant difference $(P<0.05)$ between airlifted and submerged cells under the same treatment. All experiments were repeated three times, and the data were averaged. $Y$ error bars represent the standard deviation of the averaged results.

underlying increased TLR expression in airlifted epithelial cells, we studied the response of submerged and airlifted primary cultured conjunctival epithelial cells and IOBANHC cells to the treatment of 5-ASA, an inhibitor of NFאB.

Neither primary cells nor immortal cells were able to form multilayered sheets in the presence of 5-ASA. When 5-ASA was added to the airlifted multilayered cells (4-5 days after airlifting culture), we observed an almost complete collapse of the multilayered structure $14 \mathrm{hrs}$ after the drug treatment. Airlifted IOBA-NHC cells showed higher NF $\kappa$ B activity than submerged cells (Figure 4(a)). At 5 hrs after 5-ASA treatment, IOBA-NHC cells showed decreased NF $\kappa$ B activity but little changes in TLR expression. TLR mRNA was reduced to close to the pre-airlifting level at $14 \mathrm{hrs}$ after the treatment (Figure 4(b)). However, we found no significant changes of TLR mRNA with 5-ASA treatment in monolayered cells.

3.5. Proinflammatory Cytokines Stimulated TLR mRNA Expression in Conjunctival Epithelial Cells. We examined TLR mRNA expression in submerged primary cultured conjunctival epithelial cells in the presence of $10 \mathrm{ng} / \mathrm{mL}$ TNF- $\alpha$, IL- $1 \alpha$, IL-1 $\beta$, IL-6, and IL-8; $40 \mathrm{ng} / \mathrm{mL}$ IFN- $\gamma$ alone; and $50 \mathrm{ng} / \mathrm{mL}$ of LPS. Different batches of primary cells showed different responses to cytokine stimulation. Overall, no consistent or significant changes of TLR4 and TLR6 mRNA (larger than 2fold increase in all cells tested) were detected when cells were stimulated with the above cytokines. Small increase (2-3-fold) of TLR1, TLR2, TLR3, TLR5, and TLR9 mRNA was observed when stimulated with TNF- $\alpha$ and IL- $1 \alpha$, but not with IL- $1 \beta$, IL-6, or IL-8. On average, IFN- $\gamma$ stimulated the expression of TLR3 and TLR9 mRNA by more than 2-fold, but not other TLRs. While $50 \mathrm{ng} / \mathrm{mL}$ LPS alone did not have significant effect on TLR mRNA expression, it showed synergistic effect when costimulated with some cytokines. The changes of TLR1 and TLR2 mRNA were shown as representatives (Figure 5).

3.6. Hypoxia Stimulated TLR mRNA Expression in Conjunctival Epithelial Cells. Hypoxic culture stimulated TLR2 and TLR3 mRNA expression in submerged-cultured primary human conjunctival epithelial cells (Figure 6). A 4.81-fold increase of TLR2 mRNA was observed in cells $16 \mathrm{hrs}$ after hypoxia culture and remained increased by 4.00 -fold at $24 \mathrm{hrs}$ (Figure 6). TLR3 mRNA increased 2.04-fold at $4 \mathrm{hrs}$ after hypoxia, peaked at $16 \mathrm{hrs}$, and remained elevated at $24 \mathrm{hrs}$. No changes of TLR1, TLR4, and TLR5 mRNA expression were observed.

3.7. Wounding Stimulated TLR mRNA Expression in Conjunctival Epithelial Cells. Wounding stimulated the expression of most TLR mRNA in submerged-cultured cells (Figure 7). Specifically, TLR3 mRNA increased 9.3-fold; TLR9, TLR2, and TLR6 increased 6.2-, 4.8-, and 4.2-fold, respectively. TLR5 and TLR2 mRNA increased 3.3- and 3.1-fold. However, TLR4 mRNA remained unexpressed in all three batches of primary cells tested.

\section{Discussion}

In this study, we showed that TLR expression in cultured human conjunctival epithelial cells could be stimulated by proinflammatory cytokines, hypoxia, wounding, and airlifting culture, but not by culture medium supplement. Among these, airlifting culture had the most powerful effect on TLR expression. In airlifted conjunctival cells, the expression 


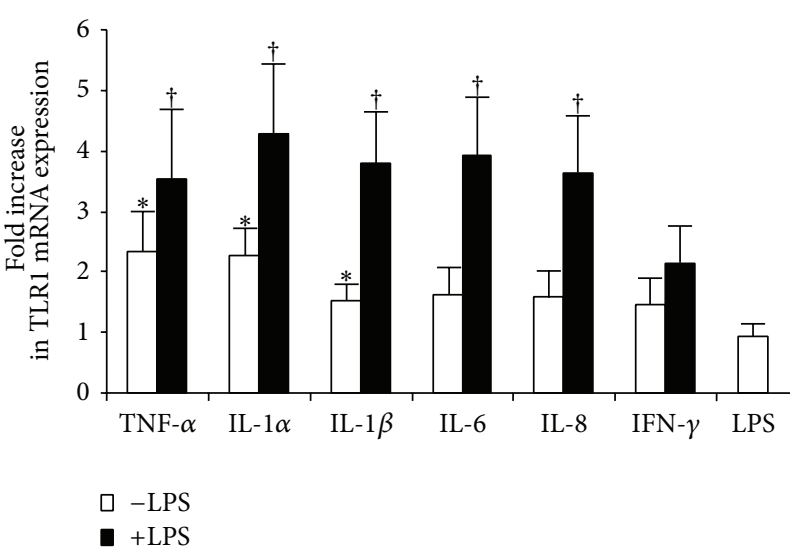

(a)

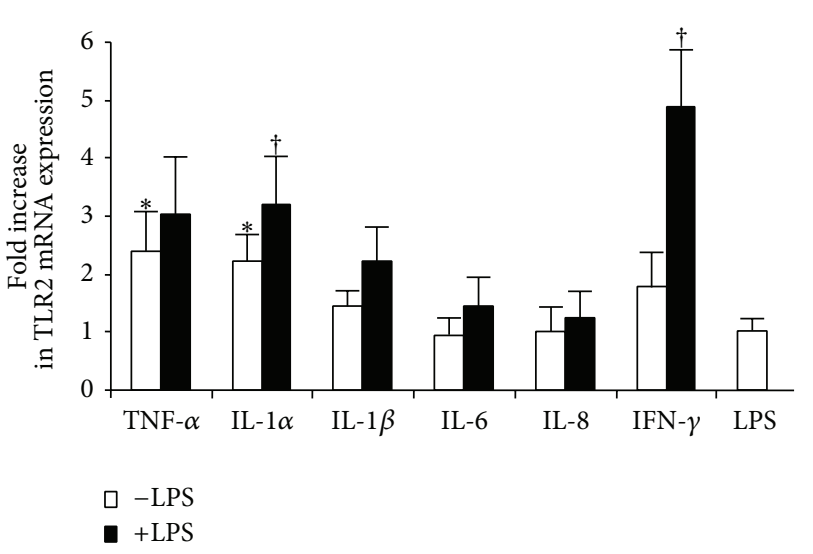

(b)

FiguRE 5: TNF- $\alpha(10 \mathrm{ng} / \mathrm{mL})$, IL- $1 \alpha(10 \mathrm{ng} / \mathrm{mL})$, IL-1 $\beta$ (10 ng/mL), IL-6 (10 ng/mL), IL-8 (10 ng/mL), and IFN- $\gamma(40 \mathrm{ng} / \mathrm{mL})$ stimulated TLR1 and TLR2 mRNA expression in submerged primary conjunctival epithelial cells with and without $50 \mathrm{ng} / \mathrm{mL}$ LPS. TLR expression in cells cultured in normal medium was used as reference for the calculation of fold increase. Open bars represent the averaged increase when cells were stimulated with cytokine alone. Solid black bars represent the averaged increase when cells were costimulated with indicated cytokines and LPS. The experiments were repeated in three different batches of cells, and the averaged results were presented. $Y$ error bars represent the standard deviation of the averaged results. Asterisks $(*)$ denote significant difference when cytokine alone was compared to that without stimulation, and $(\dagger)$ denotes significant difference when cytokine alone was compared to that with LPS.

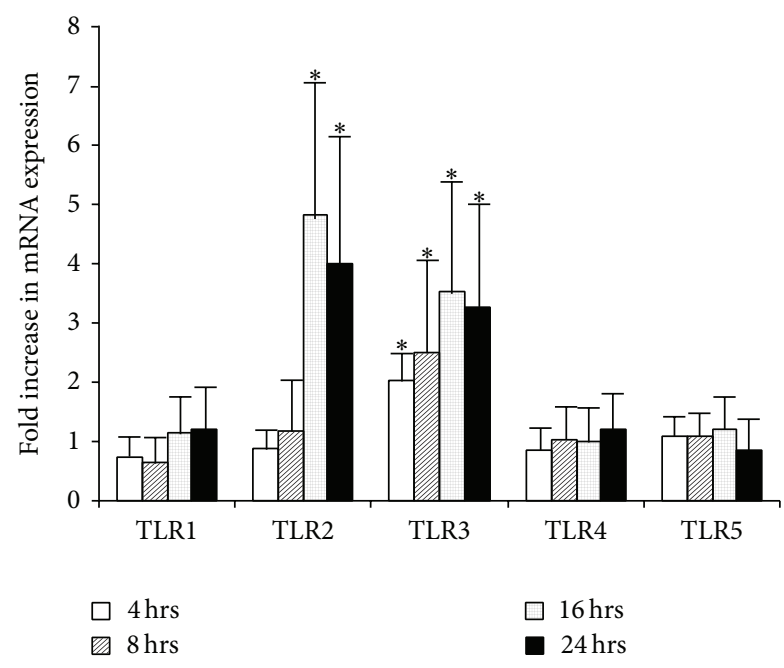

FIGURE 6: Hypoxia stimulated TLR mRNA expression in submerged primary conjunctival epithelial cells. Cells were cultured in $95 \% \mathrm{~N}_{2}$ and $5 \% \mathrm{CO}_{2}$ at $37^{\circ} \mathrm{C}$ for indicated duration before being harvested for RNA extraction and qPCR. The experiment was repeated in 3 different batches of primary cells, and the averaged changes were shown. $Y$ error bars represent the standard deviation of the averaged results. Asterisks $(*)$ denote significant difference when compared to cells under normoxia condition.

of TLR mRNA and protein was similar to what we have previously reported in vivo. Increased TLR expression in airlifted cells led to enhanced cytokine responses to low concentrations of TLR ligands, including LPS. Our study also showed that both the formation of multilayered cell sheet and

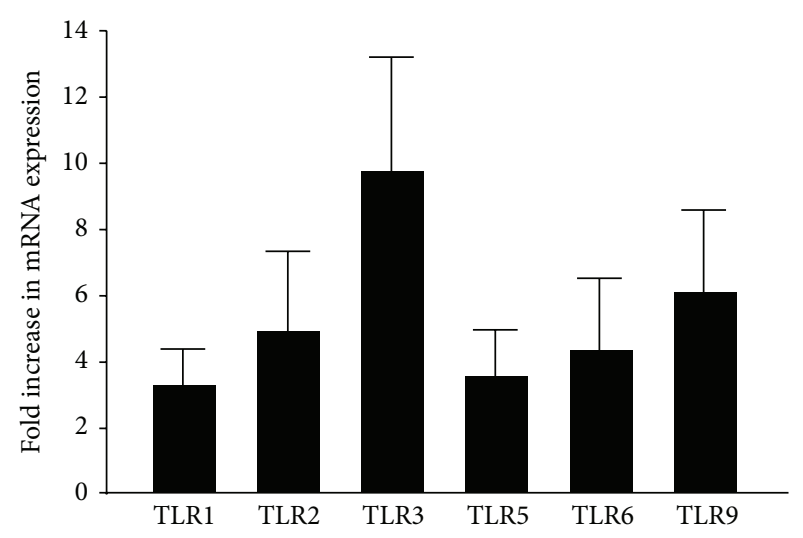

FIgURE 7: Wounding stimulated TLR expression in submerged primary conjunctival epithelial cells. Confluent cells were scratched by sterile surgical blade at about $1 \mathrm{~cm}$ interval and harvested $24 \mathrm{hrs}$ later for RNA extraction and qPCR analysis. The experiment was repeated in 3 different batches of primary cells, and the averaged changes were shown. $Y$ error bars represent the standard deviation of the averaged results. The increase was statistically significant for each TLR.

increased TLR expression were sensitive to the inhibition of $\mathrm{NF} \kappa \mathrm{B}$.

Our data suggested that TLR expression was intrinsically associated with multilayered structure formed under airlifting culture, which required $\mathrm{NF} \kappa \mathrm{B}$ activation. Airlifting culture of conjunctival and limbal epithelial cells is an effective and commonly used approach to achieve a multilayered epithelium-like structure in vitro. The multilayered epithelial cell sheets resulting from airlifting culture have 
been used as tissue graft on various ocular surface engineering applications, mostly using amniotic membrane as support $[13,14]$. Significant changes occur when epithelial tissue was digested and cells were cultured in monolayer in vitro, especially the loss of cell-cell connection. Our results indicated that the formation of multilayered structure was needed for the proper expression of TLR in conjunctival epithelial cells. Activation of $\mathrm{NF} \kappa \mathrm{B}$ was required for the formation of multilayered cell sheets. Due to the sensitive nature of airlifting culture, we were not able to further dissect the association between the formation of cell-cell connection and TLR expression at this time. However, this is not the first study which showed association between TLR expression and intact epithelial cell structure. Previous studies reported that the intestinal epithelium of TLR2 and MyD88 knockout mouse was prone to stress-induced tight junction disruption, suggesting a relationship between functional TLR and the integrity of the epithelium $[15,16]$. Low levels of TLR expression were also reported in cultured intestinal and lung epithelial cells. Unlike ocular surface, intestinal epithelium and lung epithelium contain polarized single layer epithelial cells. It would be interesting to investigate the changes of TLR in these cells under similar culture conditions.

The stimulation by proinflammatory cytokines, hypoxia, and mechanical wounding mimics the stress to which ocular surface epithelial cells may be exposed in vivo. The changes of TLR mRNA expression in cultured primary conjunctival cells demonstrated in this study suggested that epithelial cellexpressed TLR was responsive to hypoxia and wounding. The effect of proinflammatory cytokines on individual TLR mRNA expression was relatively small. We also found several studies which supported our results. For example, two recent studies described increased multiple TLR expression in mouse corneal and conjunctival epithelial cells of dry eye disease models $[17,18]$. Proinflammatory cytokines also showed stimulatory effect on human airway epithelial cell TLR2 expression [19]. However, the effect of hypoxia on individual TLR expression seemed to be different; that is, the expression of TLR2 and TLR3 was increased, while TLR1, TLR4, and TLR5 were not changed. Contradictory results were also reported on the effect of hypoxia on TLR4 expression in macrophage, endothelial cells, and corneal epithelial cells [20-22]. Further studies were needed to clarify the mechanism which mediates the effect of hypoxia on TLR expression.

In conclusion, this study identified multiple factors which regulated TLR expression in ocular conjunctival epithelial cells. Most importantly, our data suggested the existence of a coordinated reinforcement of both physical and molecular defense mechanisms during the formation of epithelial structure. Therefore, we propose that multilayered cell sheet, instead of submerged-cultured monolayer cells, is a better system to evaluate the biological activities of epithelial cellexpressed TLR.

\section{Conflict of Interests}

The authors declare that there is no conflict of interests regarding the publication of this paper.

\section{Acknowledgments}

The authors would like to thank Dr. Diebold for providing them with the IOBA-NHC cells. This research was funded by Grants from the Ministry of Science and Technology of China (the National Key Scientific Program 2012CB966901), Science and Technology Commission of Shanghai Municipality (12140903500), and SingHealth Foundation of Singapore (SHF/FG393P/2008).

\section{References}

[1] K. A. Zarember and P. J. Godowski, "Tissue expression of human Toll-like receptors and differential regulation of Toll-like receptor mRNAs in leukocytes in response to microbes, their products, and cytokines," Journal of Immunology, vol. 168, no. 2, pp. 554-561, 2002.

[2] E. M. Y. Moresco, D. LaVine, and B. Beutler, "Toll-like receptors," Current Biology, vol. 21, no. 13, pp. R488-R493, 2011.

[3] A. Abdelsadik and A. Trad, "Toll-like receptors on the fork roads between innate and adaptive immunity," Human Immunology, vol. 72, no. 12, pp. 1188-1193, 2011.

[4] A. Kumar and F.-S. X. Yu, "Toll-like receptors and corneal innate immunity," Current Molecular Medicine, vol. 6, no. 3, pp. 327337, 2006.

[5] F. S. Yu and L. D. Hazlett, "Toll-like receptors and the eye," Investigative Ophthalmology \& Visual Science, vol. 47, no. 4, pp. 1255-1263, 2006.

[6] J. Li, J. B. Shen, and R. W. Beuerman, "Expression of toll-like receptors in human limbal and conjunctival epithelial cells," Molecular Vision, vol. 13, pp. 813-822, 2007.

[7] M. Ueta, T. Nochi, M.-H. Jang et al., "Intracellularly expressed TLR2s and TLR4s contribution to an immunosilent environment at the ocular mucosal epithelium," Journal of Immunology, vol. 173, no. 5, pp. 3337-3347, 2004.

[8] J. Talreja, K. Dileepan, S. Puri et al., "Human conjunctival epithelial cells lack lipopolysaccharide responsiveness due to deficient expression of MD2 but respond after interferon- $\gamma$ priming or soluble MD2 supplementation," Inflammation, vol. 29, no. 4-6, pp. 170-181, 2005.

[9] P. I. Song, T. A. Abraham, Y. Park et al., "The expression of functional LPS receptor proteins CD14 and toll-like receptor 4 in human corneal cells," Investigative Ophthalmology \& Visual Science, vol. 42, no. 12, pp. 2867-2877, 2001.

[10] J. Li, M. Raghunath, D. Tan, R. R. Lareu, Z. Chen, and R. W. Beuerman, "Defensins HNP1 and HBD2 stimulation of woundassociated responses in human conjunctival fibroblasts," Investigative Ophthalmology \& Visual Science, vol. 47, no. 9, pp. 38113819, 2006.

[11] Y. Diebold, M. Calonge, A. E. De Salamanca et al., "Characterization of a spontaneously immortalized cell line (IOBA-NHC) from normal human conjunctiva," Investigative Ophthalmology \& Visual Science, vol. 44, no. 10, pp. 4263-4274, 2003.

[12] K. Araki-Sasaki, Y. Ohashi, T. Sasabe et al., "An SV40immortalized human corneal epithelial cell line and its characterization," Investigative Ophthalmology \& Visual Science, vol. 36, no. 3, pp. 614-621, 1995.

[13] M. Pauklin, T. A. Fuchsluger, H. Westekemper, K.-P. Steuhl, and D. Meller, "Midterm results of cultivated autologous and allogeneic limbal epithelial transplantation in limbal stem cell deficiency," Developments in Ophthalmology, vol. 45, pp. 57-70, 2010. 
[14] S. C. G. Tseng, S.-Y. Chen, Y.-C. Shen, W.-L. Chen, and F.-R. $\mathrm{Hu}$, "Critical appraisal of Ex Vivo expansion of human limbal epithelial stem cells," Current Molecular Medicine, vol. 10, no. 9, pp. 841-850, 2010.

[15] E. Cario, G. Gerken, and D. K. Podolsky, “Toll-like receptor 2 enhances ZO-1-associated intestinal epithelial barrier integrity via protein kinase C," Gastroenterology, vol. 127, no. 1, pp. 224238, 2004.

[16] E. Cario, G. Gerken, and D. K. Podolsky, “Toll-like receptor 2 controls mucosal inflammation by regulating epithelial barrier function," Gastroenterology, vol. 132, no. 4, pp. 1359-1374, 2007.

[17] H. S. Lee, T. Hattori, E. Y. Park, W. Stevenson, S. K. Chauhan, and R. Dana, "Expression of toll-like receptor 4 contributes to corneal inflammation in experimental dry eye disease," Investigative Ophthalmology \& Visual Science, vol. 53, no. 9, pp. 5632-5640, 2012.

[18] R. L. Redfern, N. Patel, S. Hanlon et al., "Toll-like receptor expression and activation in mice with experimental dry eye," Investigative Ophthalmology \& Visual Science, vol. 54, no. 2, pp. 1554-1563, 2013.

[19] A. A. Winder, C. Wohlford-Lenane, T. E. Scheetz et al., "Differential effects of cytokines and corticosteroids on Toll-like receptor 2 expression and activity in human airway epithelia," Respiratory Research, vol. 10, article 96, 2009.

[20] I. Ishida, H. Kubo, S. Suzuki et al., "Hypoxia diminishes tolllike receptor 4 expression through reactive oxygen species generated by mitochondria in endothelial cells," Journal of Immunology, vol. 169, no. 4, pp. 2069-2075, 2002.

[21] Y. Hara, A. Shiraishi, and Y. Ohashi, "Hypoxia-altered signaling pathways of toll-like receptor 4 (TLR4) in human corneal epithelial cells," Molecular vision, vol. 15, pp. 2515-2520, 2009.

[22] S. Y. Kim, Y. J. Choi, S. M. Joung, B. H. Lee, Y.-S. Jung, and J. Y. Lee, "Hypoxic stress up-regulates the expression of Tolllike receptor 4 in macrophages via hypoxia-inducible factor," Immunology, vol. 129, no. 4, pp. 516-524, 2010. 


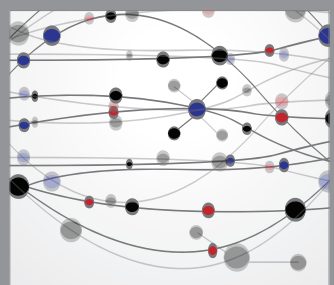

The Scientific World Journal
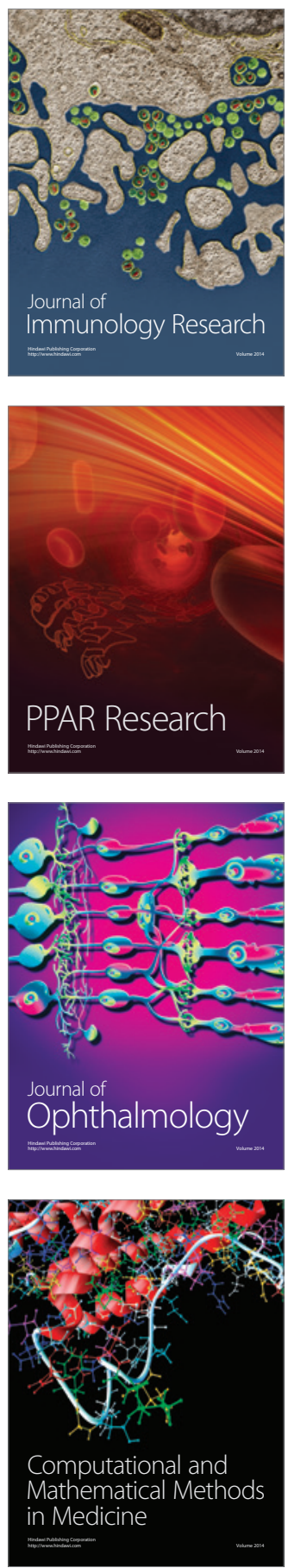

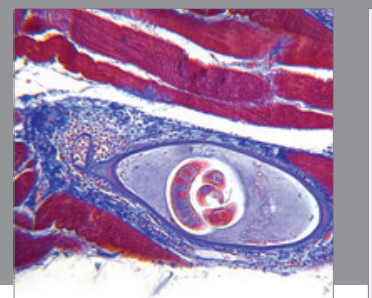

Gastroenterology

Research and Practice
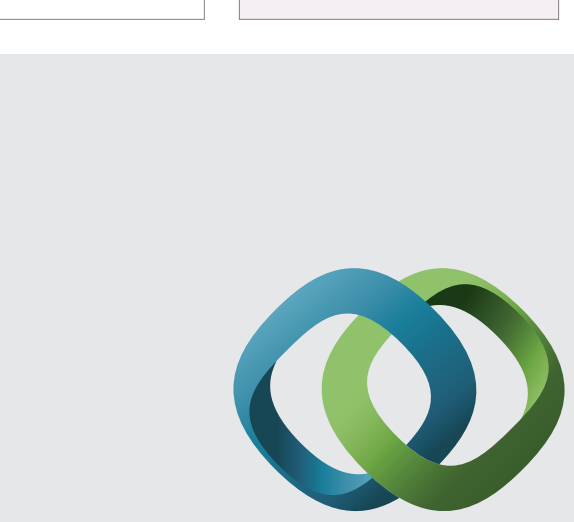

\section{Hindawi}

Submit your manuscripts at

http://www.hindawi.com
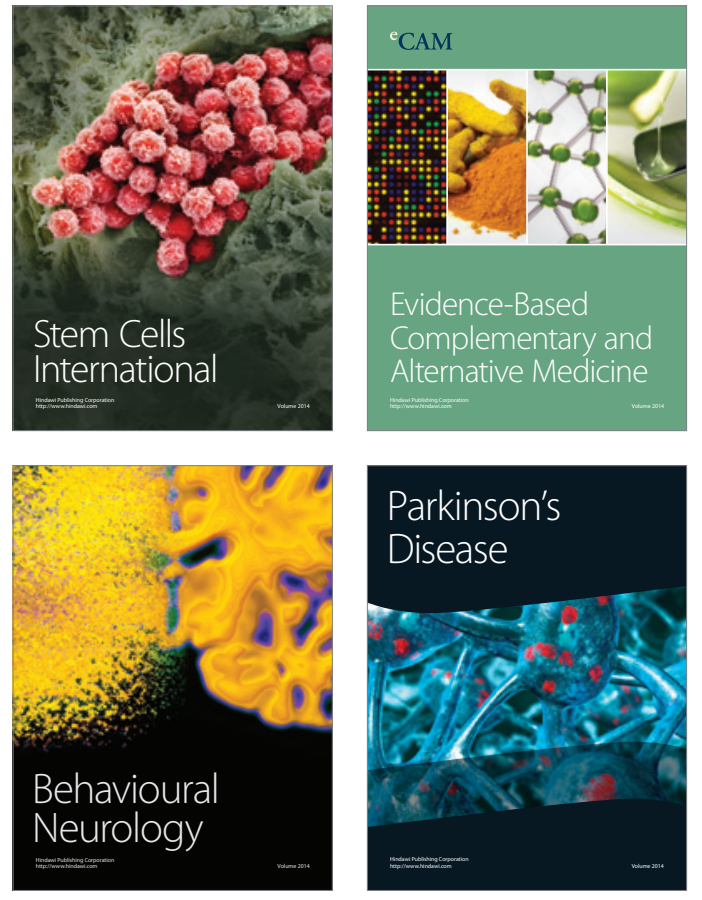
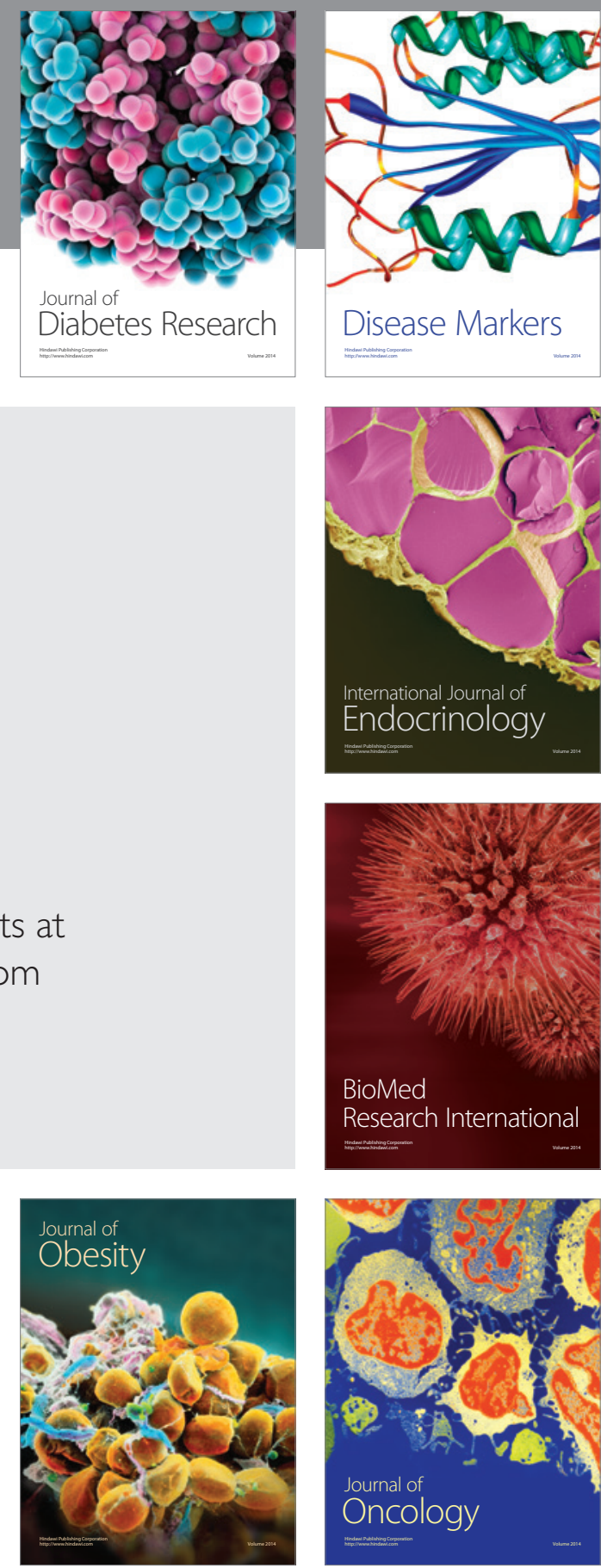

Disease Markers
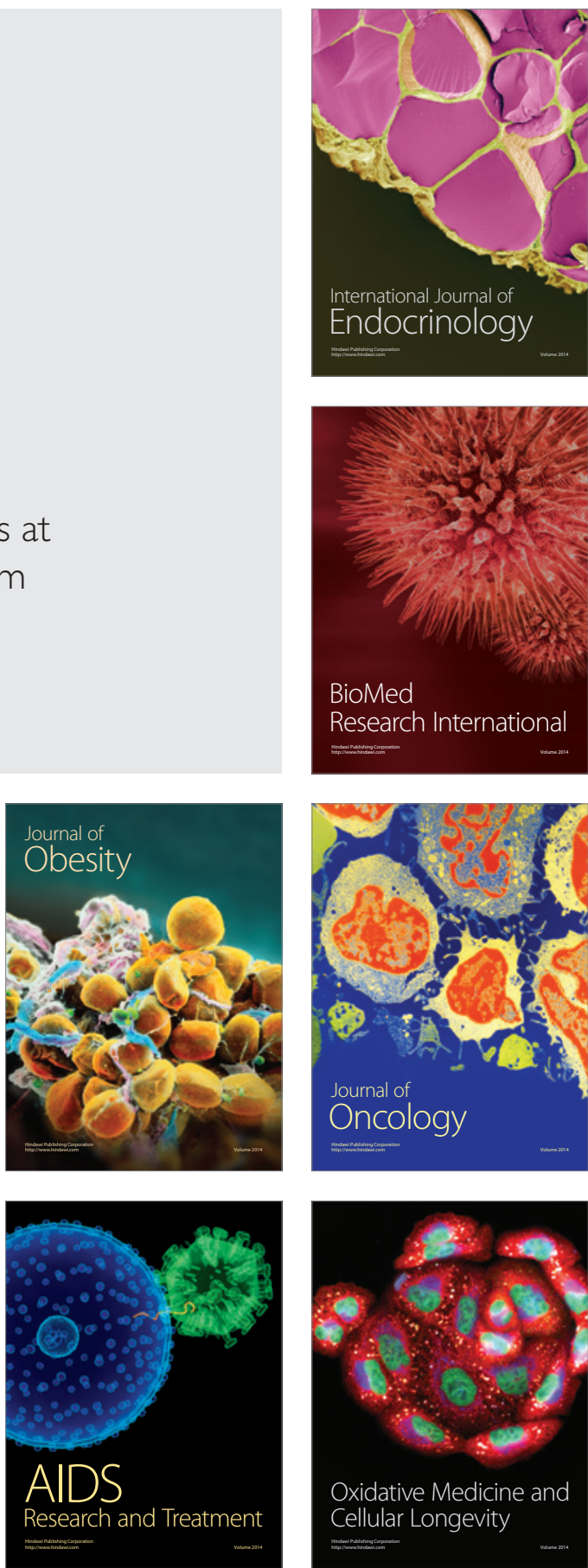